\title{
PEDAGOGIAS EM MOVIMENTO: RUMOS MEHI PARA A EDUCAÇÃO ESCOLAR KRAHÔ
}

XICUN, Secundo Tôhtôt; PÕCUHTô, Taís; TÊRKWỲJ, Juliana; TUPẼN, Leonardo, KÕNRY, Ovídio; PÊPHÀ, Ariel; CÔHTÀT, André; HERBETTA, Alexandre Hartãt; LEAL, Francy Eide; PARATY, Edvaldo; HŨ'HTÊ, Gregório JÃXY, Robertos Carlos. (NTFSI/UFG - Brasil)

Em homenagem a Xikun Secundo Krahô in memoriam

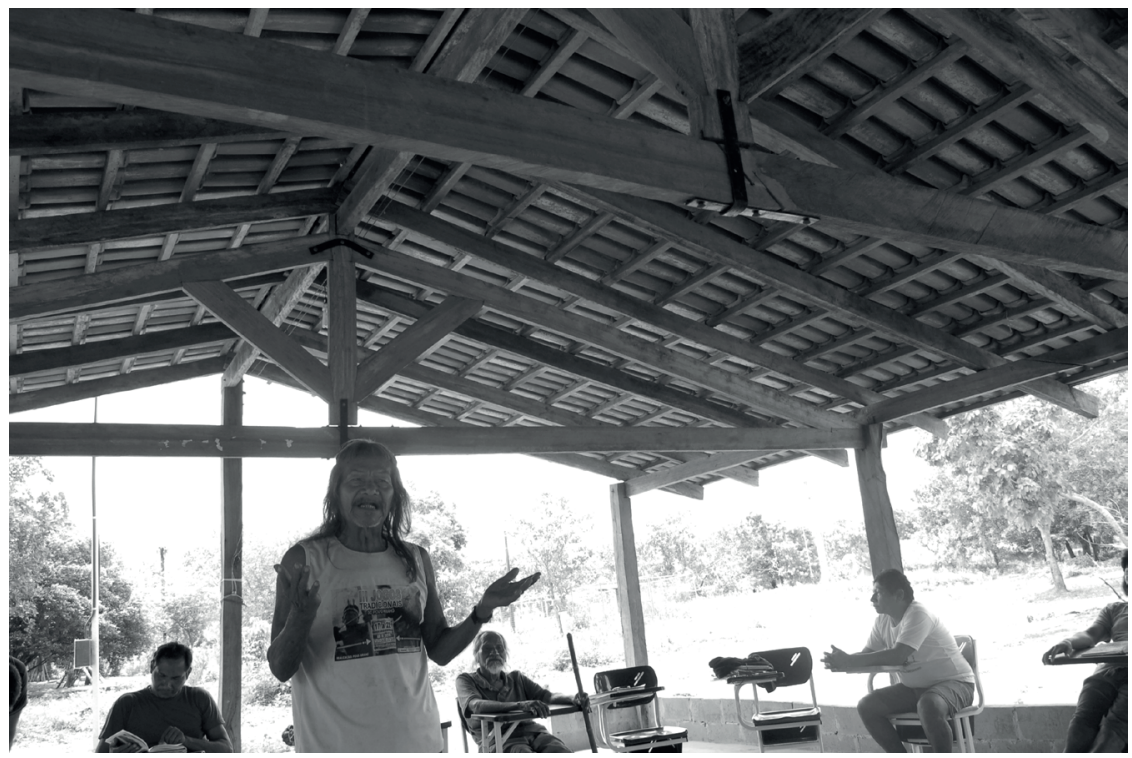




\section{RESUMO}

O texto a seguir busca sistematizar uma série nova de categorias que se referem à educação escolar indígena e, mais especificamente, à escola Krahô. Desta forma, busca-se pensar a escola Mehi (Krahô) por meio de uma nova base epistêmica, elaborada a partir do diálogo intercultural estabelecido entre populações indígenas e não indígenas no NTFSI - Núcleo Takinahaky de Formação Superior indígena, na UFG - Universidade Federal de Goiás. Tal base fica clara nas novas práticas pedagógicas e de gestão consolidadas nas escolas indígenas em referência, especialmente na Escola Indígena 19 de Abril, da aldeia Manoel Alves Pequeno e na Escola Indígena Toro Hacrõ, da aldeia Pedra Branca.

Palavras-chave: Escola. Pedagogia. Interculturalidade.

\section{ABSTRACT}

The following text seeks to systematize a new series of categories that refer itself to indigenous school education and, more specifically, the Krahô school. In this way, we intend to think the Mehi school (Krahô) from a new epistemic base, elaborated from the intercultural dialogue established between indigenous and non-indigenous populations in the NTFSI - Takinahaky Nucleus of Indigenous Higher Education at UFG Federal University of Goiás. This basis is clear in the new pedagogical and management practices consolidated in the indigenous schools in reference, especially at the 19 de abril Indigenous School, in the Manoel Alves Pequeno village and the at the Toro Hacrõ Indigenous School, in the village of Pedra Branca.

Key words: School. Pedagogy. Interculturality.

O texto a seguir expõe a tentativa do Comitê Krahô do NTFSI - Núcleo Takinahaky de Formação Superior Indígena, da UFG (Universidade Federal de Goiás), de sistematizar, de maneira ainda inicial, princípios organizadores de uma pedagogia Mehi (Krahô). Nas palavras de professores e professoras Krahô, é uma tentativa de estabelecer um rumo para a escola indígena.

O NTFSI tem nos comitês um de seus elementos centrais. Estes são constituídos por acadêmicos e acadêmicas indígenas de uma população específica, por docentes não indígenas da universidade e por anciãos e anciãs das comunidades em referência. $\mathrm{O}$ objetivo é o de, a partir de modos coletivos de atuação, produzir as atividades 
requeridas pelo Curso de Licenciatura em Educação Intercultural, pertencente ao NTFSI, como o projeto extraescolar e o relatório de estágio docência, tratar de questões de organização e logística para a realização do curso e, ademais, refletir sobre uma (nova) escola indígena. Uma escola comunitária, contextualizada e que valoriza o modo de ser de cada população.

Este texto é expresso a partir de uma estrutura baseada nos diálogos estabelecidos entre os/as integrantes do Comitê Krahô. Desta forma, tenta-se ser o mais fiel possível à dinâmica coletiva e dialógica do grupo. Busca-se ser fiel igualmente ao momento em que tais ideias e noções foram debatidas. As falas foram gravadas ao longo da etapa de estudos em TI - Terra Indígena, na aldeia Pedra Branca, em outubro de 2016. As etapas em terra indígena são momentos obrigatórios na dinâmica do NTFSI. É lá que se fortalece a relação com anciãos, comunidade, se efetivam pesquisas e se realiza a defesa do trabalho final para a conclusão do curso.

Estas falas passaram apenas por um processo de transcriação, o qual tem por objetivo adequar moderadamente o registro oral para o escrito e, ademais, tentar reproduzir a dinâmica particular estabelecida na reflexão em tela. Para Geronimo (2014),

o procedimento transcriador, portanto, despreza o sentido pontual de uma palavra isolada, para remobilizar o texto, levando em consideração o sentido no efeito de um todo. A tradução transcriadora não se contenta apenas com a "imagem do significado", mas para, além disso, acende a "imagem do seu significante", da sua "forma significante (: 1).

$\mathrm{Na}$ mesma direção, para a autora, referindo-se a Walter Benjamin, "na tradução transcriadora busca-se corresponder ao original em relação às suas características fônicas, sintáticas e semânticas mais importantes, sempre num processo de negociação" (: 3 ).

O texto-diálogo apresentado tenta preservar, portanto, uma das características mais marcantes das reflexões em referência: o movimento. É a partir da circulação das ideias e perspectivas que emerge a sistematização de uma série nova de categorias que se referem à educação escolar indígena e, mais especificamente, às escolas Krahô - como a ideia de balanço entre os temas contextuais e as disciplinas, a noção de esticar e atualizar o conhecimento, a importância do pátio e de outros espaços para a aprendizagem, o 
papel dos anciãos e anciãs na educação escolar e a necessidade do movimento.

Para os Krahô, aprende-se em movimento. Tal premissa problematiza dualidades reificantes em uma matriz eurocêntrica de conhecimento (LANDER, 2005, pp. 8-24), como a divisão entre o corpo e a mente e entre a razão e a emoção.

O movimento Mehi que tem a ver com todos os temas referidos pode ser simbólico ou cognitivo, quando os temas trabalhados na escola vão do intra ao intercultural, como em um fluxo contínuo que se articula entre a tradição e a contemporaneidade. Pode ser também concreto ou cinético, quando a aula acontece no pátio, em projetos de pesquisa ou na corrida de tora que movimenta os corpos. Deve, na verdade, ser ambos. Simultaneamente.

Nesta mesma etapa de estudos, contamos com a ilustre presença do ancião Xicun Secundo Krahô. Xicun é uma das principais lideranças Mehi. Ele participou ativamente de todos os momentos-movimentos importantes desta população nas últimas décadas - desde os contatos com a FUNAI (Fundação Nacional do Índio), a relação com outras populações indígenas, a mediação com o cupê (não indígena), a fundação de novas aldeias e a formação de novas lideranças. Muitos dos acadêmicos Krahô que cursam o NTFSI são, inclusive, seus parentes.

Ele domina o repertório de histórias, músicas, objetos, organização social e festas Krahô. Como dizem, é uma "biblioteca viva". Generosamente, nunca se recusou a participar das etapas de estudo e das pesquisas de seus parentes sobre os Krahô, a escola e o mundo.

Secundo faleceu repentinamente em março de 2017, deixando seus parentes Mehi e seus amigos cupê profundamente entristecidos. Talvez nunca tenha havido um sábio tão solidário, amável, bem humorado e forte. Ele permanecerá, entretanto, na memória, no coração e na prática cotidiana de todos que o estimaram.

Este texto é uma singela homenagem a este grande líder Mehi, fundamental igualmente no processo de escolarização da aldeia Manoel Alves Pequeno e na formação de várias gerações Krahô. Fundamental como se verá para a pedagogia Mehi. O movimento começa com ele. Salve Xicun! 


\section{Xicun jarkwa ${ }^{1}$ :}

ỹhỹ! Amcro ita kãm hapuhnã mẽ atuw mã ate mẽ amjĩ kãm ajapac xà ita, mẽ amã ihkĩn kottô, mẽ amã cute amjĩ kãm hapac xà kĩn kottô, mã paape ita kãm hahkwa ita kĩn kottô, nãm hã ca tahnã mẽ amjĩ pupu. Pê mãm hajỹr nare! Nãm hã ipê akrãhtõm, ipê apãm, ramã iwejtu! Nẽ ha ajpên wrỳm nõ, wrỳm itajê kôt hamrẽare, quirmã pê cupẽ itajê cato, quirmã! Pê amẽ hahêr jipy mã pê cormã ajpên itar cupẽ ita cato! Mũṽ! Mũṽ wrỳm, mũṽ (Posto) jĩkjê rũmpê wrỳm pê mãrhã mẽ anõ mã hahkrepej nare. Ma hîkjê rũmpê mã pê wa icato, nẽ wrỳm ita pupu, cormã curi, nẽ cormã! Nẽ ramã ampo jahkre pej tu. Nẽ ajpên mẽ rê nẽ ( Posto) krac ri cormã mẽ ahtwỳ. Pea pê cormã (Posto) ita cato. Mẽhĩ jõh Posto. Chefe do posto kãm cato. Nãm hãã ramã hapuhnã, ca amẽ impeaj to, ramã mẽ apãm jê jarkwa, mẽ apupxwỳjê jarkwa pic tor ra ipic tor, ha ramã mẽ harkwa kĩn nẽ mẽ krĩ xàre jarkwa kĩn, nã wa amẽ akãmpa, krĩ xàre jarkwa kĩn, ihkĩn catêjê to ca amẽ acaakôc, amẽ to Apinaje caakôc xà mã: ỳw ita! Mã ra hapuhnã, wa ramã apu ahkrajre impar to ipa, kãm mẽ to: ỳw! Ca ha jũm cukij quê ha to amã: ỳw! Nẽ tahnã nare, aric ri: ỹhỹ, hajỹr nare mã ỳw!, kãm mẽ imã, ramã ijĩ itã kãm mã ramã ampo ito ( trapaj = atrapalhar) "ihkrãh mãj nare", ( só) ihnõ quê ito ihkên, cupẽ jarkwa kãm, ixàh nõ quê itô ihkên, wa nõ nẽ kãm amẽ ato pa. Jưri mẽ cuprõ, rama ite amjĩ mã amjĩ kãm ijapac xà ita to amjĩ mã ijopên tu, ate nãm hãã ituwa hũm ( Hũhtê), ỹhỹ! Ca ha krĩ (Aldeia Cachoeira) kãm mẽ cuprõ, wa ha ma icato ijĩ ita to! Jũri hipêr mẽ cuprõ, wa ha ijĩ ita to mẽ akôt icato! Amcro ita kãm ca nẽ. Nãm hã wa hamṽ amẽ akwỳ kãm pa, quê mẽ hanẽ, wa amẽ akwỳ kãmpa, hãã mẽ ihkàreh nõ quê ahheaj nã mẽ pah wỳr cato, quê mẽ ihnõ nã ahwỳ quê ahheaj nã nẽ mẽ pa mã pry jarẽ, ahheaj nã mẽ pa mã mam mẽ pa inquêtjê hêmpej xàh nõ jarẽ! Hamrẽare, wa amjĩa kôt ajpên kwỳ! Akrãhtõm! Aprequêtti ihtỳj itar pra nẽ hapôj, (Aldeia Manoel Alves) kôt hapôj nẽ ra ite hahkrepej tũm kôt, imã hõmpun prãm, impej! Xà pàt impej, nã pê mẽ anã cato, nẽ tahnã mã impej, tahnã mẽ amã hõt pê ihhim pej xà to, mã ca mẽ harkwa caca nare, ta hõt pê mẽ acaxuw amjĩ to ( professor) ihkàhhôc hõr catê nã amjĩ to mẽ acaxuw, nẽ mẽ ato amjĩ tê. Nẽ ihcuhkwỳr nẽ hapôj, nẽ cupê ihkwỳ nare, cupê ihkwỳ

1 Agradecemos à Letícia Jokàhkwyj Krahô, mestranda do PPGAS/UFG, pela transcrição da fala. Agradecemos a Tais Põcuhtô, graduanda do NTFSI/UFG e Dodanin Piiken Krahô, egresso do NTFSI/UFG, pela revisão e correção da fala. 
nare! Wa apu ihcaakôc xà nã kãmpa! Impej crinare te hajỹr!!! Quê nẽ incryc nare, incryc xà to ihcaakôc nare! Harkwa caprĩu, hohcajrẽn, nẽ impeaj, kãm cute amjĩ kãm hapac xà impej, ca hõt pê mẽ ampo kwỳh nã, mẽ pa inquêtjê jarkwa, ca hẽt pê mẽ to hamã, nẽ ihkwỳ ramã mẽ pa pê ipic tor par, ca amẽ impeaj to, ca ita caxuw, mã ca mẽ. Nẽ hapuhnã caxuw, mã ca mẽ paape ita kãm ramã mẽ to anõ quê nẽ ipic tor nare. Ramã hõõkre caro pro xà ita kãm (gravações) ita nãm hã paape ita, ca kãm ihcaakê quê nẽ uuu nẽ ipictor nare, ca ha tahnaa ty! Quê ha pactoan paape kãm tahnaa impej ita nã. Hõ, hopên xà (trababalho) to hopên xà ita tahnã impej ti ihkrĩ, ca ha tahnã ajamrẽ, quê kra mã mẽ akra, atàmxwỳjê, mẽ akra mã mẽ to intuw to mẽ ipa, mã to intuw to ipa! Jũm japac kre mãn japên, ate mẽ amjĩ kãm ajapac xà ita to ihcaakôc, mẽ ajakàn pê, mẽ ajarkwa ita to ihcaakôc, ihhimpej xà ita to ihcaakôc, mẽ ahhimpej xà ita quê ha harẽ! Ita wỳr mã ca mẽ to mõ, ita wỳr mã ate ramã mẽ cumã acator to mõ! Nẽ ramã mẽ, mẽ pa jarkwa mẽ, mẽ pa jĩ jarkwa mã cormã huja kràj nõõre pean cupẽ te amjĩ kãm hapac xà harkwa mã ramã ihkàhtu nẽ mẽ pahkĩn te ihhipej xà johkêt. Ihhêmpej xà, mẽ pa mã, mẽ pah caakôc xà ita pijakrut, pean caa ca ha ampo kãm to amji jarĩh pyrentu, nẽẽ to amji pê mẽ pah hêmpej xàh nõ cuto, nẽ hapuh nã amjĩ mã acryc, wa apu icaakôc nare, ijapactu nẽ nẽẽ to icaakôc nare! Hõh pahte mẽ hajỹr! Pea nẽ cupẽ mã ihkrã incrinaare, ampo caxuw wa amjĩ mã ( Jogo, bola ti ) caxuw ihhimpej xà ita johkêt, wa ikrĩ nẽ apu kãm pa, ihkôt hakop, amjĩ kãmpa, ampo pyxit nare, kôt wa kãm imã hamrẽ nare kôt, itar imã ca amẽ apa, mẽn mẽẽ wa mẽ apupun to tẽ, wa mẽ apupu, pê ajrom ajtea imã hũhpjêr xà, wa pytwrỳ kãm pra nẽ mẽ apupu (xeman) kãm pra nẽ mẽ apupu xãm cute hajỹr nare ahhêh nã ita kãm hõtpê imã amjĩ jahkrepej pỳm wa ajpên tẽ,atõ caj prỳre, akrãhtõm cajprỳre ito tẽ!Nare xãm wa amjia kôt tẽ, nẽ jũm te imã, hã wa ma (carro) nõh nã ahwỳ ca kãm tẽ hajỹr prãm nare, wa amjĩa krã kôt tẽ ijõh ihpooreah kãm tẽ, kãm hapỹ mã quê ha kra akrãhtũm ita amjĩ jõõ nã ixô nẽ Ito tẽ, inã amjĩ xô nẽ ito tẽ. Hõõ cutê hajỹr! Ra ate mẽ ipar, impej, ite mẽ ikwỳh kĩn te, ite amjĩ kãm ijapac xà ita to amji kãm ijapac to apu ipa, wa mẽ apupu nẽ mẽ apyrên ijakry to icuhkwỳr!! Ca mẽ hanẽan to mẽ honẽ! Hõ ite amjĩ kãm ijapac xà ita mã. Hamrẽ!!

Hartãt: Tem os conhecimentos cupê (não-indígena), tem os conhecimentos Mehi, vocês falam muitas vezes isso, tem dois mundos. Como lidar com esses dois mundos? Tem que ter matemática, física, química, português, história, filosofia, ou não? Mas, também, 
tem que ter música, as festas, conhecimento do cerrado, a natureza, como lidar com esses dois mundos aparentemente diferentes? Vocês criaram uma solução que eu acho fantástica, que é fazer um balanço. Por exemplo, a Escola 19 de Abril, tem um balanço: uma semana trabalha com a dinâmica disciplinar, uma semana a dinâmica do Tema Contextual. Na escola Panrã da Aldeia Nova eles estão criando um balanço no PPP (Projeto Político Pedagógico): 6 meses de disciplina, 6 meses de Tema Contextual. Esse balanço, pelo menos no meu entendimento, tem a ver com o modo próprio de organização do mundo Mehi, que é o balanço das metades: Wacmejê e Catàmjê. Então, de certa forma, talvez a gente possa falar que um dos aspectos da pedagogia Mehi é o de conseguir fazer esse balanço, esse equilíbrio entre esses conhecimentos. Essas perguntas estão abertas para vocês colocarem o que vocês acham que é a pedagogia Mehi, se esse balanço é um aspecto dessa pedagogia e o quê mais tem essa pedagogia?

Wathur: Vou falar o que entendo sobre pedagogia Mehi. A pedagogia Mehi eu entendo que ensina o jovem pelo nome e pela pintura do seu partido e da natureza, quando a criança aprende de pequeninho a saber qual é seu grupo, quem ajuda carregar a tora, porque o Mehi tem esse seu conhecimento, então, nós Mehi, nós temos uma pedagogia. Porque toda pedagogia do cupê busca dominar a escola indígena e a aldeia. Devemos preparar os alunos para buscar onde as frutas estão, qual o local onde eles podem buscar essas frutas. É isso que eu entendo que os homens também têm que ensinar, preparar os alunos para não ficarem dependendo do cupê, só esperando a comida da cidade, tem que procurar como antigamente, tem que fazer a caça, caçada e produzir seu próprio alimento. É isso que eu entendo por pedagogia. A gente quer preparar o Mehi, valorizar a própria cultura e o conhecimento próprio. É esse que é meu entendimento de pedagogia.

Cuxy: Nós queremos que nossa escola tenha sua própria visão de entender o nosso mundo, então a gente tem que ter mais conhecimento, junto com os mais velhos. Muitas vezes os mais novos já não conhecem os parentes, já não conhecem a natureza, já não conhecem o que nós vemos no mundo. É difícil entender o nosso mundo sozinho, mas com o conhecimento dos mais velhos, que eles sempre vêm repassando de geração em geração. A gente 
tem percebido muita coisa que está desaparecendo. Nesse momento a gente tem que pensar e buscar esse conhecimento que está desaparecendo, tem que pesquisar os mais velhos sobre a história. Lá mesmo na minha comunidade, quando eu vejo que as crianças já começam a chamar os parentes pelo nome, isso me preocupa. Nós não queremos deixar eles perderem os termos de parentesco. Nós temos que orientar as crianças para que conheçam essas práticas dentro da comunidade, porque é difícil a gente passar esse conhecimento, mas a gente tem que ensinar várias vezes, incentivar várias vezes para que eles possam entender. Esse conhecimento que nós temos é um valor que deve ficar para sempre. Eu não quero que desapareça. Tantas coisas que os mais velhos sempre contavam já não existem mais. Nós temos que buscar, temos que pesquisar várias anciãs e anciãos, que estão até agora vivos. Nós temos que pegar esse nosso conhecimento. Nós temos que mudar a nossa escola dessa forma.

Pephá: Vou falar um pouco da parte de pedagogia que eu entendo. $\mathrm{Na}$ verdade, como meu colega falou, nós estamos esquecendo nosso parentesco. Nós queremos resgatar e ensinar nossos alunos, porque, na verdade, o branco cupê ensina a parte dele. Nós queremos registrar isso que estamos quase esquecendo.

Tupen: Então vou falar um pouco da pedagogia Mehi. As aulas do povo Mehi são em todos os lugares, não é só na escola, e não é só na escrita também. Todos os conhecimentos são passados na oralidade. Antes, as nossas culturas eram fortes, porque não tinha escola, como vocês estão vendo hoje. Para que os Mehi cresçam sabendo de tudo, educados na lei do Mehi. Tudo começa dentro de casa, com a família e hoje nós não estamos vendo isso mais. O pessoal pensa que é a escola que vai ensinar tudo isso. A escola está para educar. Tem muitas festas, tem muitas culturas que se deve aprender. E a escola hoje está mais dominando o conhecimento do não indígena, os cupê, pela dinâmica da disciplina. Por isso, todas as nossas culturas estão cada vez mais fracas. Graças a Universidade - UFG -, é através dela que nós estamos lá na Escola Indígena 19 de Abril. Mostramos para os cupê de fora, para os cupê de Itacajá, que nós ainda temos essa energia que é resistência, com força de mandar na escola. Por isso que eu acho muito importante ter a semana de tema contextual. Eu continuo falando e vou continuar falando, se nós pararmos de trabalhar com o tema contextual a escola volta daquele jeito. Os jovens não vão 
aprender mais nada, os jovens vão acompanhar o conhecimento dos brancos. Para que a nossa pedagogia seja forte, o nosso único jeito é pegar os sábios, os experientes, cantores, pajés, esses profissionais que conhecem a realidade, o movimento dos povos Krahôs e levar para a sala de aula. Convidar os alunos para ouvir, para praticar, para realizar, botar em prática os conhecimentos dentro da escola. Sem a escola o jovem de hoje não vai aprender mais nada. Vão deixar dentro deles mesmos a cultura deles morrer, mas com a ajuda da escola, com a ajuda dos professores, com ajuda dos anciãos, sábios, eles podem recuperar, nós podemos recuperar. Meu tio Dodanin fala que as nossas culturas não morreram ainda. São como água, está ali parada, mas se nós movimentarmos a nossa cultura, ela volta a ser praticada. Não daquele jeito, mas volta a praticar. A gente fala muito bem as nossas línguas, tem os anciãos que sabem fazer as festas que não estão mais fazendo. Na escola podemos voltar a movimentar. É isso que eu penso de pedagogia Mehi. É tudo através dos sábios. No caso, eu não sei fazer a festa, mas pesquisando eu consigo. Isso é o que fortalece os sábios experientes, cantores, cantoras, pajés. Através das pesquisas pode fortalecer a pedagogia do Mehi.

Cotath: Eu também vou falar um pouco da pedagogia Mehi. Como eu sou professor e trabalho na escola, eu estou fazendo pedagogia Mehi. Não só na escrita, eu procuro pessoas para pesquisar, pesquisando os mais velhos. Saindo da escola e procurando outros conhecimentos. Ali dentro da escola não tem. A pedagogia do Mehi não é só na sala. $\mathrm{O}$ mais importante pra mim é que a pedagogia Mehi é uma cultura muito forte, que faz com que todos os alunos, as crianças, possam aprender. Como meu pai sempre diz: Tinha aula, tinha disciplina dos cupê, mas o mais importante era ficar na cultura, por isso ele não aprendeu a escrever, não aprendeu a ler. O mais importante para ele, naquele tempo, naquela época, era mais a cultura mesmo, músicas, danças. Isso era uma pedagogia. Porque a nossa pedagogia está na natureza mesmo, sempre. Não só nos livros, mas livre, na natureza, onde todo Mekraré (ancião) vinha aprendendo. Hoje mesmo eu não sei a pintura, só sei aquela pintura na horizontal. Dos outros tipos eu não sei. Onde se tem a pintura das crianças, dos músicos, dos mais velhos. Não sei qual é a pintura dos mais velhos, não sei qual a pintura dos jovens, não sei a pintura dos Wacmejè. Isto porque não estamos praticando e estamos usando mais a pedagogia cupê, como roupas. A pedagogia mais voltada para a natureza Mehi não tem a ver com as disciplinas. 
Paraty: Então, a pedagogia Mehi, eu vou falar um pouquinho. Minha preocupação é sobre a língua. Sempre me preocupei com a fala, com nosso idioma. O português chegou e ficou atrapalhando a língua indígena. Além disso, me preocupo com a caçada. É muito Mehi que pensa que a caça é fácil, mas não é fácil. Eu vou andar no campo, vou conhecer as árvores, os animais. É o conhecimento da natureza. Tem a regra, a norma, para poder praticar, se não, fica perdido, entra no mato e fica perdido. Tem que planejar o caminho para chegar e encontrar os animais.

Xôhtyc: Eu acho muito importante ter o balanço entre os mundos aqui na aldeia Pedra Branca, porque, se só disciplinar, a gente não vai para frente, a gente não vai ter visão da nossa própria cultura. Nós somos indígenas, professores indígenas, e temos que valorizar mais o tema contextual, para que a gente possa conhecer mais o conhecimento Mehi, por exemplo: a caçada, a pesca e cultura, a festa, o ritual, artesanato e língua também. A gente quer valorizar para ter mais conhecimento daqui de dentro. Ter autonomia. A gente tem que criar nossa autonomia, dentro da nossa comunidade. Então, eu preciso ter esse balanço, para a gente equilibrar. Por exemplo, uma semana só tema contextual com Mehi, professores indígenas, movimentando a escola. Com disciplina, só os cupê movimentando na sala de aula. Isto, para poder comparar e aprender juntos. Com o tema contextual aparece muito conhecimento que quase já foi perdido. Atualiza, né, o que está arquivado, o que os colegas falaram que está parado. A gente tem que atualizar. Para atualizar tem que somar, pesquisar os mais velhos nas aldeias, que nem o Secundo. Precisa juntar o conhecimento tradicional para poder aplicar no tema contextual. Registrar também no audiovisual e no livro também, para fazer pequenas cartilhas. Tem que movimentar bem, fazer acontecer mais tema contextual na sala, na aldeia também. Tem o calendário, Mehi gosta de fazer festa cultural, porque na chuva é difícil de fazer cultura Amjk kĩn. $\mathrm{Na}$ época da seca, entre junho e agosto é o mês de fazer Amjk kĩn, festa grande. Eu penso que seria na seca o tema contextual. E na época da chuva só na sala de aula, de modo disciplinar. Tem que ser na pedagogia Mehi, nós temos que ser o autor agora, pesquisar mais Mehi e publicar. Levar as coisas para Mehi e movimentar a comunidade e a escola. A escola movimenta a comunidade, a comunidade movimenta a escola também, juntos. Esse é meu pensar. 
Jaxy: O elemento principal da pedagogia Mehi é o mais velho. Para montar uma pedagogia Mehi é importante ter a participação dos mais velhos porque a escola não cria sozinha, a escola não vai criar nada sozinha, a escola só repassa, só executa os conhecimentos buscados lá fora. Esses conhecimentos estão nos mais velhos, nas outras regiões, nos outros povos, na mata, nas histórias contadas pelos mais velhos. Tem as dominações que cada partido faz e a escola pode trabalhar junto com elas, esse movimento que o partido faz, as histórias contadas. Cabe resgatar mais histórias para serem repassadas nas escolas, muitos projetos estão sendo feitos nos negócios de resguardo, caçada, cantiga, casamentos. Cantiga é muito bom, aí dentro desse tema há varias historias. Cupê só tem aquele objetivo, falar sobre o que tá ali no livro, ele tem que seguir aquilo não tem outra preocupação, é por isso que ele aprende e não quer dar importância para uma outra vida, um outro conhecimento. Ele só quer saber daquilo que aprendeu, não que saber de seres diferentes, povos diferentes. Ficar classificando, com preconceito.

Acàkwyj: Vou falar um pouco da pedagogia Mehi. E do balanço. Antigamente os jovens respeitavam os mais velhos, quando os mais velhos falavam umas coisas eles respeitavam, mas hoje não. No Krin (aldeia) já se usa o português, não se fala mais Inxu, eles chamam de pai, de mãe. Dentro da escola as crianças aprendem a respeitar. Eu estava no outro Krin e tinha uma criança que a mãe falava pra ele e ele não ouvia. Respondia para a mãe com palavras ruins. Eu ficava muito triste. Isso é falta de respeito. Antes os mais velhos faziam festa e tinham aquele respeito, os mais velhos falavam, os mais novos não podiam responder, não. Na escola tem a disciplina e tem o tema contextual. Meu último tema foi sobre a música. Eu os ensaiei, e me apresentei com eles. Nós apresentamos a música do Peixe. As crianças gostaram muito da música.

Ropcuxy: A escola não indígena tá muito forte. Nossa língua tá baixa e a do cupê tá lá em cima. Então, nós temos que ver isso aí para ter balanço, conhecer o lado do cupê e do Mehi também. Eu mesmo não pinto mais, eu não corto o cabelo. Essa é a dominação do cupê que tá na nossa região Krahô. Essa minha fala é isso, a gente tem que pesquisar. E só pra finalizar; porque sobre nossa língua; eu já fiz uma pesquisa que cada aldeia tem uma fala também, aí muda de ano em ano. Aqui já mudou várias palavras, não tá falando mais 
àquela palavra que ouvi antes. Lá na aldeia Cachoeira fala de outra forma, lá na aldeia Manoel Alves a fala é de outra forma, lá no Paraty é de outra forma, lá no Morro do Boi é só cupê. Quando eu chego lá, falo só cupê.

Huhtê: Eu vou falar aqui para inteirar, reiterar o que os colegas colocaram sobre as principais características da pedagogia Krahô, destacando a dinâmica do tema contextual. Se a gente for falar do tema contextual tem que falar de tudo o que a festa envolve, tem o jeito de contar, como funciona e tem o objetivo para mulheres e para homens. Na Aldeia que eu moro a gente tem cultura viva. Eu falo como mestre, porque aqui na área Krahô eu percebo que nós temos três mestres ainda que a gente chama de padré. A gente tem que ter o aproveitamento deles para colocar na sala de aula. Porque tudo tá na aldeia. A nossa aldeia é formada como o mundo. Por isso a aldeia Krahô é sempre redonda. O pátio é central como o sol e a estrada representa o raio. Nós temos duas divisões, como o professor colocou, Catàmjê e Wacmejê. A gente pega no pátio e tem que levar para a sala de aula. Hoje eu tenho um professor Mehi que dá aula na língua, toda sexta-feira ele dá aula. Então, sexta-feira ele tem que trabalhar, ele dá aula sobre caçada, na outra sexta-feira ele vai dá aula sobre organização social indígena. Se a gente ficar dependendo da educação dos cupê, não é bom para nós. Acabamos de falar do parentesco, porque nós temos essa denominação de considerar nossos parentes. Eu sou casado e minha mulher não pode me chamar de Huhte. Eu também não vou chamá-la pelo nome dela. Eu tenho que chamar de acordo com o nome do primeiro filho. Eu já tenho uma menina, ela tem que chamar considerando o nome da menina. Se a gente não fizer isso, as crianças de hoje vão perder tudo. Eles falam na língua, mas eles não sabem aprofundar o que o mais velho declara. Para a gente mudar, passar pro contexto, a gente tem que esticar, a gente tem que esticar para que os alunos entendam melhor. E também não só sobre essas variações que eu estou colocando, mas dentro da nossa língua também, na nossa fala nós temos um conjunto de padrões de acordo com o que você vai falar ou dizer. Porque a gente tem que saber separar para poder fazer com que as nossas crianças entendam melhor. A gente começa a falar ali e já coloca português. Tem que exigir mesmo, a gente tem que correr atrás, se a gente não fizer, a gente vai perder música, história, língua, artesanato, festa tradicional. Porque em cada tempo 
nós temos a forma de fazer a festa, a gente tem que falar sobre a colheita de fruto, tem que falar sobre as caçadas, a pescaria, sobre as músicas. Porque tem lugar certo, você tem que cantar aquelas músicas, tem a música que o pessoal vai correndo e quem está vindo atrás tem que cantar aquela música. É bonito também, muito bonito, escuta-se de longe a tora vindo. Esse é o nosso papel, isso garante que a gente tem que seguir. $\mathrm{O}$ que nós podemos fazer é construir e deixar para que a próxima geração continue fazendo. Porque tudo o que está na educação do cupê nós temos na educação Mehi, mas o problema não está na escrita, não é uma coisa assim visível. Por exemplo, o vento balançando numa folha, o vento balançando numa folha você não percebe, mas você tem aquele sentido, sabe o que o vento tá fazendo. Então, tem muita disciplina, isso tudo a gente tem que colocar no papel e pegar assim, não somente na escola, mas a gente tem disciplina dentro da casa, tem disciplina dentro do Krin, tem disciplina dentro da roça, tem disciplina dentro do mato, tem disciplina dentro e fora. A escola tem que pensar e fazer algo sobre isso.

Terkwjy: Vou falar um pouco da pedagogia Mehi. Eu já ouvi o que alguns disseram, mas eu discordo de algumas partes. Defendo a nossa cultura. A nossa cultura ainda é forte, na Manoel Alves ela ainda é forte. A nossa cultura é forte por parte dos velhos anciãos de cada comunidade. Eu acho que às vezes eles falharam em ensinar os jovens. Porque eles são os conhecedores de todos os rituais e por essa parte eles falharam. Por isso está acontecendo isso de as nossas línguas estarem em perigo. Mas não está acabando, não está acabado ainda. É para isso que somos pesquisadores, nos tornamos pesquisadores para pesquisar e não para pôr somente na escrita. Porque com certeza se estiver só na escrita como será na prática, no dia a dia? Se não existissem os anciões tanto daqui como do meu Krin, eu não iria conseguir a minha pesquisa. São bibliotecas vivas. A gente sabe, somos os próprios Mehi. A nossa cultura ainda é forte, tem alguns rituais que estão parados, só parado. Tem que movimentar, mas ainda é forte, só está parado porque ainda tem alguns anciãos que sabem. Sabem também da língua, dos parentescos, das músicas, dos rituais. Só está parado, tem que movimentar. É para isso que a gente trabalha com temas contextuais com a nossa Escola Indígena 19 de Abril que é uma referência para todas as escolas. Antes, nos tempos do SPI, a escola prendia os jovens, não dava liberdade. A 
escola cupê prende mesmo. Eu até estudei, eu sei um pouco porque a escola me prendia, eu não tinha essa liberdade de pesquisar minha mãe, minha avó. Eu acho que a escola cupê prende, faz com que aluno não veja a realidade sua, a cultura, sua cultura, seu costume. Acaba desvalorizando a sua própria cultura. Os anciãos, os sábios, as lideranças têm que se movimentar para ser forte. Nossa cultura ainda é forte. $\mathrm{Na}$ minha comunidade a gente já trabalha com o tema contextual e ensina os jovens a valorizar a cultura, não esquecendo a cultura do Mehi, nem do cupê. Tem um balanço. Porque nesse mundo a gente tem que conhecer a cultura do Mehi e do cupê. Se a gente aprofundar somente em nossa cultura, no futuro quem vai defender a gente? Se ficarmos por fora dos nossos direitos, quem vai defender? Por isso que a gente tem que levar os dois, a nossa e a do cupê. Eu acho isso muito importante, porque meu pai vem falando isso para gente. Nesse Krin, passando esses três dias, eu aprendi muito, eu já tenho outro conhecimento. Aqui eles têm que querer e ser forte para trabalhar com o tema contextual. Porque o tema realmente deve ser trabalhado na escola. $\mathrm{O}$ tema contextual ajuda muito e eles vão ter o resultado que eles querem como a gente tem hoje em nossa escola. A gente tem o resultado que a gente sempre queria. É muito Impej o tema contextual, porque, o tema contextual faz com que a gente veja o outro mundo, a partir de nossa realidade. Ele abre a visão. Antes, eu não tinha essa preocupação com minha cultura, eu desvalorizava minha própria cultura e valorizava mais a cultura do cupê pensando que eu estava no caminho certo. Mas eu não tava no caminho certo. $\mathrm{O}$ tema contextual é muito Impej. É o balanço, porque a gente tem que balançar.

Pocuhto: Eu vou finalizar. Cada um de nós tem uma opinião própria, temos um conhecimento próprio, nós sabemos as coisas diferentes. Quando eu vejo uma palavra que eu não concordo eu anoto. A gente quer uma escola Krahô. Se a gente quer uma escola diferenciada ou uma escola do cupê depende de cada professor que atua na sua comunidade. A gente tem que ter muito cuidado quando fala pro jovem. Quando eu tô aprendendo uma coisa e erro, se alguém falar pra mim, eu fico muito triste. Isso magoa as pessoas, porque somos humanos, sentimos vergonha, pahan, nos sentimos triste. Tem que tomar cuidado. A gente tem que ter nossa educação do povo Krahô. Porque a gente tem que se preocupar com as nossas crianças, porque a gente já foi criança e hoje somos jovens e futuramente seremos anciãos da comunidade. Como que eu vou ser um ancião? Eu vou ser um ancião sábio ou um ancião que tem um conhecimento vazio? Isso vai 
depender de cada um de nós. Aprendemos um com o outro. Quando eu olho para uma pessoa e vejo o lado dela vazio e eu não posso fazer nada. Nada será completado. Quando eu tô vendo que aquela pessoa não está se desenvolvendo eu tenho o papel de ajudar e como a gente trabalha com o tema contextual no nosso Krin, não somente na sala de aula, a gente aprende. Nosso pátio é uma escola, a rua é uma escola, a natureza é uma escola, tudo é uma escola própria do povo Krahô. A gente tem que tratar as crianças como seres humanos, como Mehi. Eu aprendo quando alguém me ensina, se não me ensinar eu não vou aprender. Então tem coisas que eu não aprendi porque ninguém me ensinou e tudo que eu sei é porque teve alguém que me ensinou. A gente tem que ensinar pros nossos alunos a ter o respeito pelo próximo, a ter respeito pelos anciãos. Assim, acima de tudo o respeito é mais importante de tudo. O respeito quando tiver uma festa cultural. Se eu não gosto de cortar cabelo, mas eu gosto de pintar, se eu não sei correr, mas eu canto. Se cada aprendizagem é diferente, então a gente procura trabalhar com nossas crianças de uma forma equilibrada. A gente ensina duas coisas, do cupê e do Mehi. Ele tem que aprender ler, ele tem que conhecer coisas que não é Mehi. Ninguém é isolado. Quando eu for trabalhar o tema contextual tenho que ter uma justificativa. Por que eu quero trabalhar com aquele tema? Por exemplo, se eu quero trabalhar com o ritual Pephak, tem que ter uma justificativa. Eu tenho que ter um roteiro, o que eles devem fazer, tem que entrevistar quem, quem participa. Tem que ter preocupação com todas essas coisas. Quando eu me aprofundo na cultura do Mehi, eu vou respeitar. Eu acho que dentro do tema contextual a gente valoriza muito a nossa cultura, a gente arquiva, memoriza. Somos jovens. A gente tem que se preocupar com essas coisas, trabalhar com criança, valorizar a própria cultura, conhecer o cupê. Essa é minha fala. Hamré.

\section{REFERÊNCIAS BIBLIOGRÁFICAS}

GERONIMO, Vanessa A Teoria da Transcriação de Haroldo de Campos: O Tradutor como Recriador - Vanessa Geronimo. QORPUS. Edição no 13. Periódico Vinculado à Pós-Graduação em Estudos da Tradução da UFSC. 2014.

LANDER, Edgardo. Colonialidade do saber: eurocentrismo e ciências sociais. Perspectivas latinoamericanas. Edgardo Lander (org). Colección Sur Sur, CLACSO, Ciudad Autónoma de Buenos Aires, Argentina. Setembro 2005. 
